University of Nebraska - Lincoln

DigitalCommons@University of Nebraska - Lincoln

Entomology Papers from Other Sources

Entomology Collections, Miscellaneous

1988

\title{
Ultrastructural Studies of the Abdominal Plaques of Some Diptera
}

John G. Stoffolano, Jr.,

Department of Entomology, University of Massachusetts, Amherst

Norman E. Woodley

Systematic Entomology Laboratory, USDA-ARS, norman.woodley@ars.usda.gov

Art Borkent

Biosystematics Research Centre, Agriculture Canada, Central Experiment Farm

Lucy R. S. Yin

Electron Microscope Laboratory, Massachusetts Agricultural Experiment Station, University of Massachusetts, Amherst

Follow this and additional works at: https://digitalcommons.unl.edu/entomologyother

Part of the Entomology Commons

Stoffolano, Jr.,, John G.; Woodley, Norman E.; Borkent, Art; and Yin, Lucy R. S., "Ultrastructural Studies of the Abdominal Plaques of Some Diptera" (1988). Entomology Papers from Other Sources. 92.

https://digitalcommons.unl.edu/entomologyother/92

This Article is brought to you for free and open access by the Entomology Collections, Miscellaneous at DigitalCommons@University of Nebraska - Lincoln. It has been accepted for inclusion in Entomology Papers from Other Sources by an authorized administrator of DigitalCommons@University of Nebraska - Lincoln. 


\title{
Ultrastructural Studies of the Abdominal Plaques of Some Diptera
}

\author{
JOHN G. STOFFOLANO, JR., ${ }^{1}$ NORMAN E. WOODLEY, ${ }^{2}$ \\ ART BORKENT, ${ }^{3}$ AND LUCY R. S. YIN ${ }^{4}$
}

\begin{abstract}
Ann. Entomol. Soc. Am. 81(3): 503-510 (1988)
ABSTRACT Light microscopy revealed cuticular plaques restricted to the abdomens of both sexes of four species of brachycerous flies: Tabanus nigrovittatus Macquart, Apiocera barri Cazier, Hydrophorus viridiflos (Walker), and Dolichopus consanguineus (Wheeler) Using SEM, these plaques proved glabrous and unsculptured. Only at high magnification did they show small pits. TEM of the plaques showed the cuticle in this region is traversed by numerous muscle attachment fibers which extend from just below the epicuticle to the base of the cuticle, where they connect to the microtubules of the tendinous epidermal cells. These fibers or tonofibrillae serve as the attachment sites for underlying muscles. In our study, however, no muscles were found in the older adults examined. Based on comprehensive examination of museum specimens and the presence of plaques only in the Nematocera and orthorrhaphous Brachycera, we suggest that these plaques were sites of attachment for muscles used by the pupa for abdominal movements that assist in locomotion and for muscle action that assists the pharate adult in rupturing the pupal case for eclosion. Following emergence, these muscles degenerate in a programmed cell death. Absence of the plaques in the Muscomorpha (Cyclorrhapha) is postulated to be a synapomorphy for this group of flies, correlated with their immobile pupa and different mode of emergence.
\end{abstract}

KEY WORDS Insecta, abdominal plaques, tonofibrillae, phylogeny

THE TEMPERATURE RECEPTORS of horse flies (Diptera: Tabanidae) have not been located (Dethier 1957). Consequently, in 1983 we began an investigation to locate them in the salt marsh greenhead, Tabanus nigrovittatus Macquart. Prior to our studies, however, we found a reference by Bromley $(1926,456)$ on the external anatomy of the black horse fly, Tabanus atratus $\mathrm{F}$., in which he stated "sculpturings or the so-called sense-pits are present in definite areas of both tergites and sternites. Their significance is not clearly understood" (Fig. 1). Because Evans \& Kuster (1980) reported on the infrared sensory pits of the black fire beetle, $\mathrm{Mel}$ anophila acuminata DeGeer (Coleoptera: Buprestidae), which at the light microscope level are similar in shape to the "sense-pits" of T. nigrovittatus, we decided to examine, using a scanning electron microscope (SEM) and a transmission electron microscope (TEM), the so-called sense-pits of Bromley to see if they were thermoreceptors. As the study progressed, however, contact with N.E.W. led to the discovery that these "sense-pits" occur on virtually all flies in the suborders Nematocera

Department of Entomology, University of Massachusetts, Amherst, Mass. 01003.

${ }^{2}$ Systematic Entomology Laboratory, USDA-ARS, \% U.S. National Museum NHB 168, Washington, D.C. 20560.

${ }^{3}$ Biosystematics Research Centre, Agriculture Canada, Central Experiment Farm, Ottawa KlA 0C6 Canada.

${ }^{4}$ Electron Microscope Laboratory, Massachusetts Agricultural Experiment Station, University of Massachusetts, Amherst, Mass. 01003 and Brachycera "Orthorrhapha." Thus, their function as thermoreceptors was questioned.

Here we report the results of our examination of the "sense-pits" using SEM and TEM, and our survey of museum specimens of Diptera to discover how widely the pits are distributed within the order. Our examination and survey suggest a function for these structures. Throughout the remainder of this report, we use the term "plaque" rather than "sense-pit" because we feel that these structures serve no sensory function.

\section{Materials and Methods}

Tabanus nigrovittatus females were collected from the salt marshes of Essex County, Mass., using visual box traps (Granger 1970), and males were obtained by sweeping. Other flies for SEM studies were museum specimens preserved in $70 \%$ ethyl alcohol provided by one of us (N.E.W.).

Flies for SEM studies were either taken through to $100 \%$ ethyl alcohol (preserved specimens) or were air-dried (dead specimens from traps and sweeping), and were coated with gold-palladium using a Polaron Sputter Coater (Polaron Instruments, Line Lexington, $\mathrm{Pa}$.) and scanned with an ISI Super III electron microscope (International Scientific Instruments, Avon, Conn.).

Postemerged T. nigrovittatus females were fixed for TEM with $2.5 \%$ glutaraldehyde in $0.1 \mathrm{M}$ sodium cacodylate buffer and postfixed with $1 \%$

This article is a U.S. government work, and is not subject to copyright in the United States. 
$\mathrm{OsO}_{4}$. Specimens were dehydrated through an ethanol series and embedded in Spurr's medium. Thin sections were stained with uranyl acetate and lead citrate and examined with a Zeiss EM9S2 electron microscope.

A survey of museum specimens was conducted to ascertain how widespread the cuticular plaques are within the Diptera. A total of 112 families of Diptera was examined-essentially all those listed in chapter 1 of the Manual of Nearctic Diptera (McAlpine et al. 1981). In addition, the families Perissommatidae, Pantophthalmidae, Sciadoceridae, and Ironomyiidae, which occur only outside the Nearctic Region, were examined. The survey was not exhaustive within families; in general, two to five genera were examined from each. Usually more genera were examined in those families in which plaques were not observed.

The terminology used to describe the plaques was taken from Harris (1979); our concept of the Muscomorpha follows that of McAlpine et al. (1981). Voucher specimens of $T$. nigrovittatus have been deposited in the museum collection of the Department of Entomology, University of Massachusetts, Amherst.

\section{Results and Discussion}

Fig. 1 shows a line drawing taken from Bromley (1926) and a SEM photograph taken in our laboratory of abdominal plaques found in a female $T$. atratus. These confirm that the plaques of our study are the same as those described by Bromley. SEM photographs of female (Fig. 2-5) and male (Fig. 6 and 7) $T$. nigrovittatus showed that the plaques are located only on the abdomen, occur in both sexes, are glabrous and unsculptured (i.e., exhibit no cuticular outgrowths; Fig. 4 and 7), and show pitting of the cuticle only at higher magnification (Fig. 5). The pits of the plaque shown in Fig. 5 are about $400-1,300 \AA$ in diameter. SEM photographs of three other species-Apiocera barri Cazier (Apioceridae), Hydrophorus viridiflos (Walker), and Dolichopus consanguineus (Wheeler) (Dolichopodidae)-clearly show these plaques on the abdomen and their similarity to those of $T$. nigrovittatus (Fig. 8-13). In all these species, the plaques varied in size ( $\boldsymbol{T}$. nigrovittatus female, 25 by 80 $\mu \mathrm{m} ;$ T. nigrovittatus males, 15 by $75 \mu \mathrm{m} ;$ A. barri, 23 by $75 \mu \mathrm{m} ; H$. viridiflos, 40 by $75 \mu \mathrm{m}$; and $D$. consanguineus, 35 by $70 \mu \mathrm{m}$ ) and location. The plaques of $T$. nigrovittatus and A. barri are more numerous (20-50 per segment on each side), irregular in shape, and scattered over the abdominal tergites and sternites (Fig. 2 and 8); whereas those of $H$. viridiflos and $D$. consanguineus are fewer (3-4 per segment on each side), more regular in shape, and located only on the lateral edges of the tergites (Fig. 10 and 12 ).

In our survey of the Diptera, the plaques were observed in all seven infraorders of Nematocera

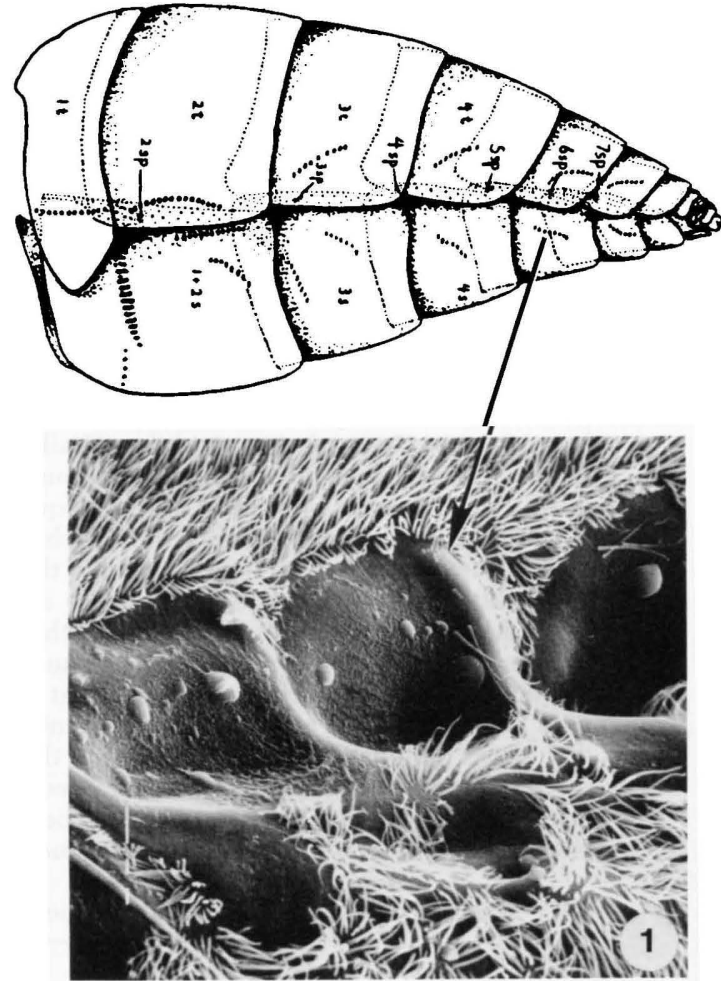

Fig. 1. Line drawing taken from Bromley (1926, Fig. 10) showing the "sense-pits" on the abdomen of Tabanus atratus. The indicated group of plaques on segment 5 in the line drawing is shown below in an SEM photograph of a female Tabanus atratus. (Line drawing used with permission of the Entomological Society of America.)

but not in all families. Plaques were not found in Blephariceridae, Deuterophlebiidae, Bibionidae, Mycetophilidae, Psychodidae, Scatopsidae, Synneuridae, or Culicidae. It is entirely possible that the plaques occur in some of these families but were obscured by their small size or the dense vestiture.

We observed plaques in all families of the brachycerous infraorders Tabanomorpha and Asilomorpha except the Acroceridae. Members of these taxa are generally larger in size, facilitating observation. All 66 families of the infraorder Muscomorpha (=Cyclorrhapha) examined lacked the cuticular plaques. Consistent with our SEM studies, the plaques in all museum specimens examined were glabrous and unsculptured and occurred in both sexes.

Thus, the SEM studies and museum survey changed our original hypothesis that these plaques were temperature receptors. Because they are found on both sexes of tabanids and only females take blood meals, doubt was cast that they were temperature receptors. In addition, the plaques occur widely in nonhematophagous Diptera, spanning virtually the entire ecological breadth of the order. 

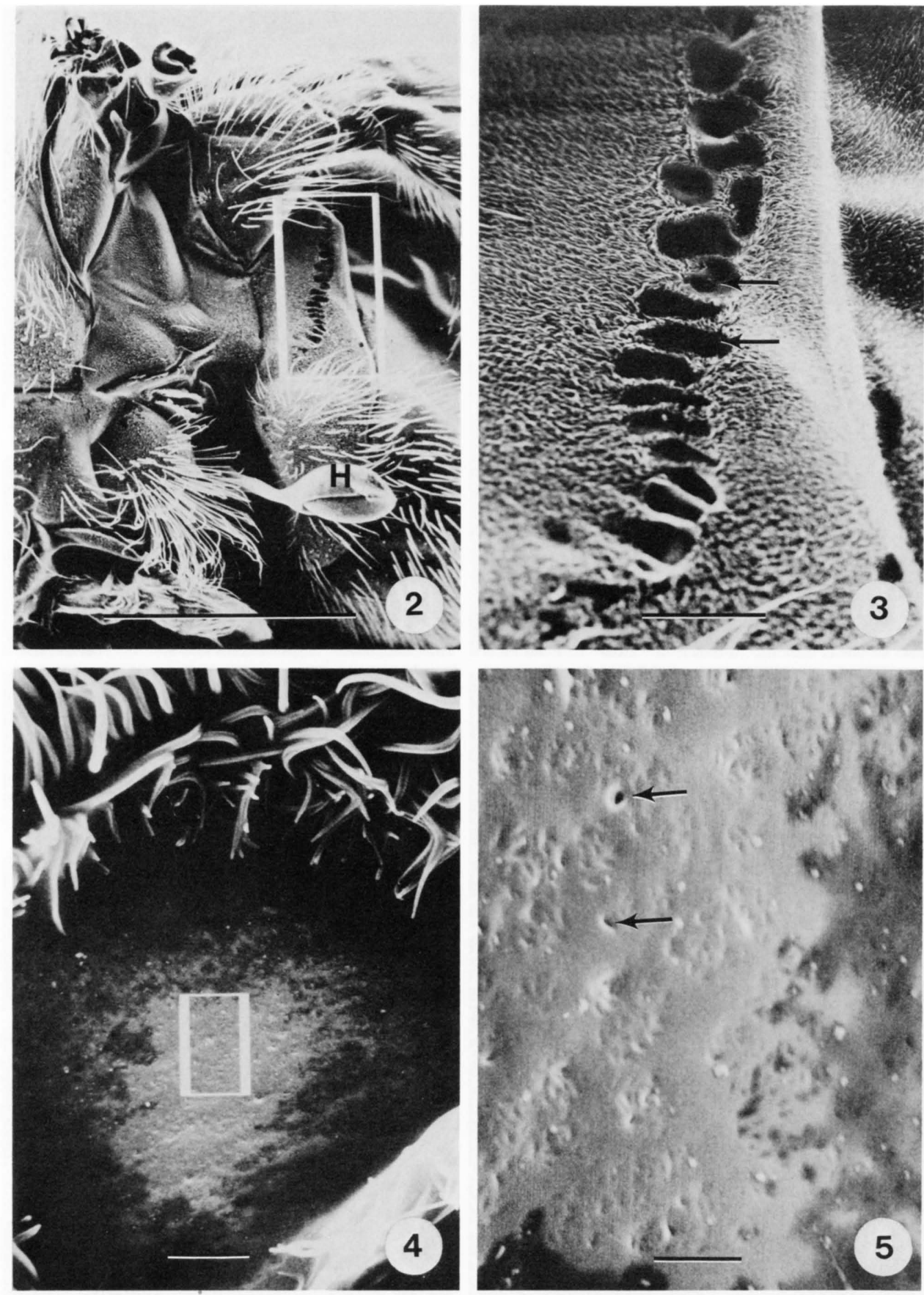

Fig. 2-5. (2) Ventral view of Tabanus nigrovittatus, female, showing the first abdominal sternite and a haltere (H). The series of plaques are shown within the frame. Bar, $1 \mathrm{~mm}$. (3) Higher magnification of the framed region in Fig. 2, showing at least 20 plaques (arrows) lacking cuticular outgrowths. Bar, $100 \mu \mathrm{m}$. (4) Higher magnification of one of these plaques, surrounded by cuticular outgrowths in the adjacent area. Bar, $10 \mu \mathrm{m}$. (5) An enlargement of the framed area in Fig. 4, showing the pitted surface of the cuticle (arrows). Bar, $1 \mu \mathrm{m}$.

This also casts serious doubt on any possible thermoreceptor function.

We then studied cross sections of the cuticle of $T$. nigrovittatus with TEM. The region outside the plaques showed a typical arthropod cuticle devoid of vertically oriented fibers (Fig. 14). In the plaque region, however, we were surprised to find numerous vertically oriented fibers extending from the base of the cuticle to the epicuticle (Fig. 14 and 15). In addition, these fibers continued below 

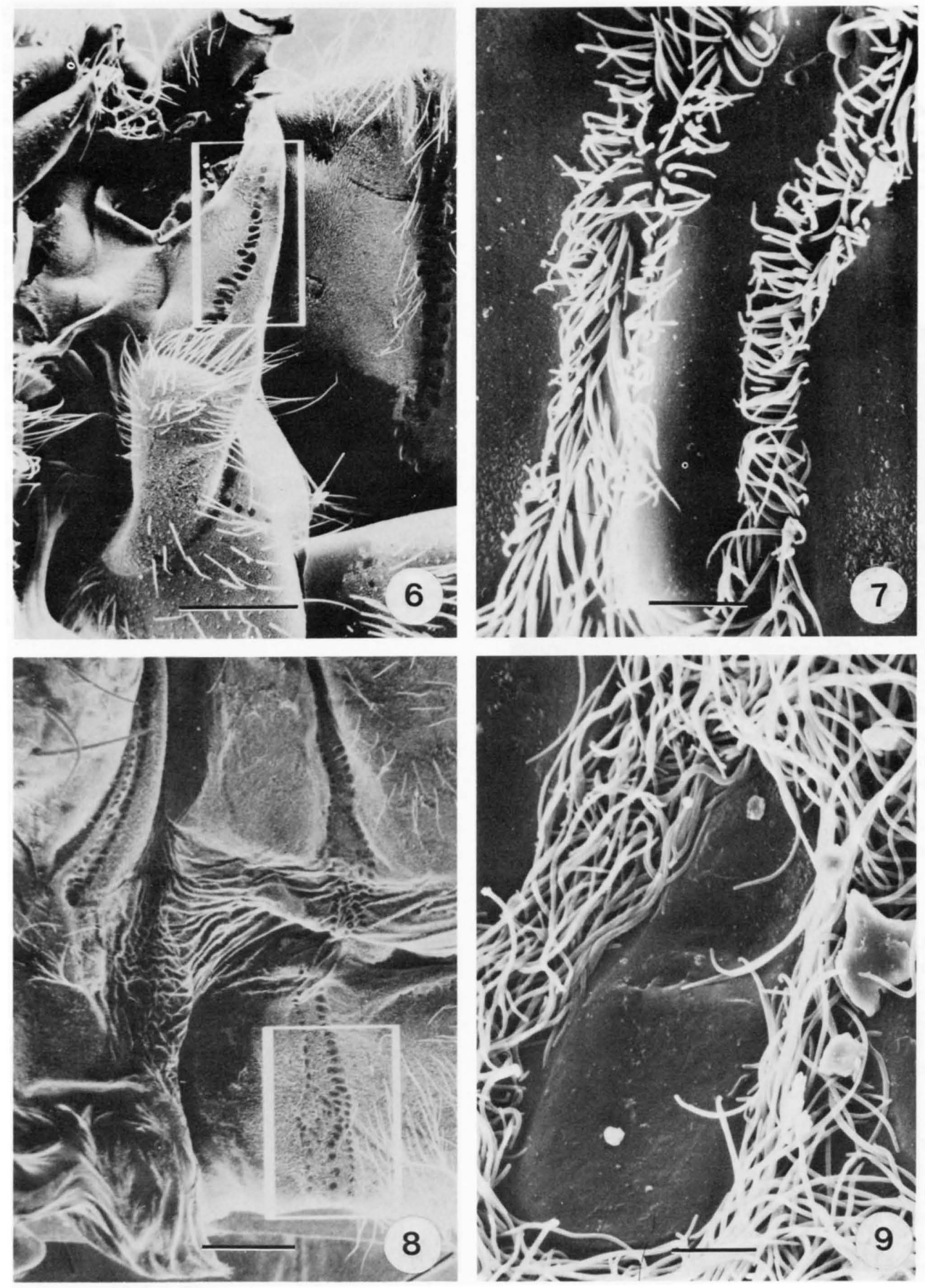

Fig. 6-9. (6) Ventral view of Tabanus nigrovittatus, male, showing the first and second abdominal sternite. At least 20 plaques (within frame) are shown on first sternite. Bar, $0.5 \mathrm{~mm}$. (7) Higher magnification (of Fig. 6) of some plaques devoid of cuticular outgrowths but surrounded by cuticular outgrowths. Bar, $10 \mu \mathrm{m}$. (8) Ventral view of Apiocera barri Cazier (Apioceridae) showing the first and second abdominal segments with series of plaques. Bar, $0.5 \mathrm{~mm}$. (9) Higher magnification of a plaque shown in Fig. 8, also showing the cuticle devoid of cuticular outgrowths. Bar, $10 \mu \mathrm{m}$.

the cuticle and into the underlying epidermal cells (Fig. 16). In epidermal cells adjacent to or outside the region of the plaque, these fibers were lacking (Fig. 14 and 16).
These fibers actually are specialized epidermal cells (termed "tendinous epidermal cells" by LaiFook 1967) containing numerous microtubules (Fig. 17) which usually provide the connection between 

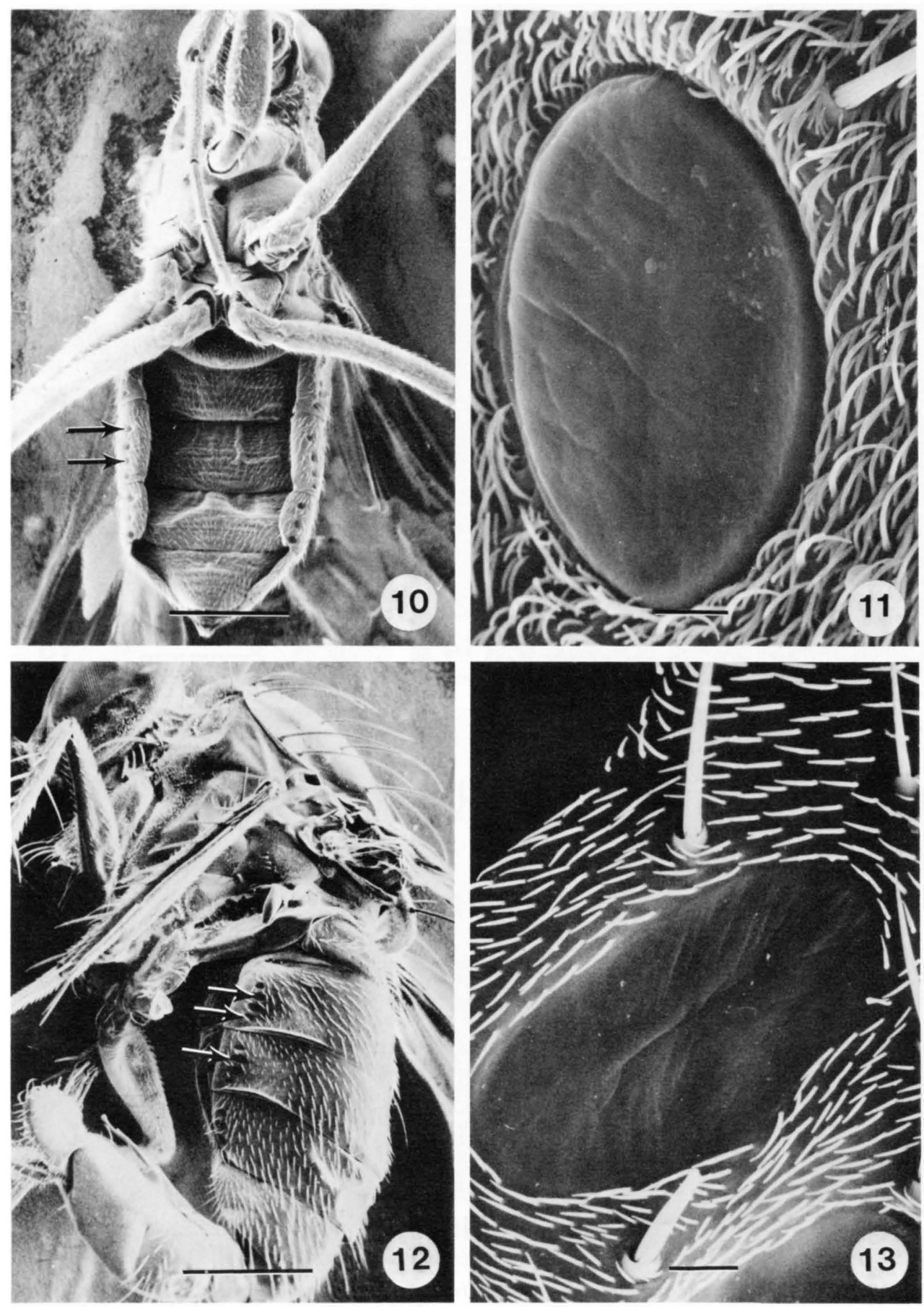

Fig. 10-13. (10) Ventral view of Hydrophorus viridiflos (Walker) (Dolichopodidae), female, showing rows of oval-shaped plaques on lateral edges of tergites (arrows). Bar, $1.0 \mathrm{~mm}$. (11) Higher magnification of one of the plaques shown in Fig. 10, showing the lack of cuticular outgrowths; however, some slender indentation of the cuticle is apparent. Bar, $10 \mu \mathrm{m}$. (12) Lateral view of Dolichopus consanguineus (Wheeler) (Dolichopodidae), male, showing rows of oval-shaped plaques located on the lateral edges of its tergites (arrows). Bar, $1.0 \mathrm{~mm}$. (13) Higher magnification of the plaque shown in Fig. 12, which is also devoid of cuticular outgrowths. Bar, $10 \mu \mathrm{m}$. 

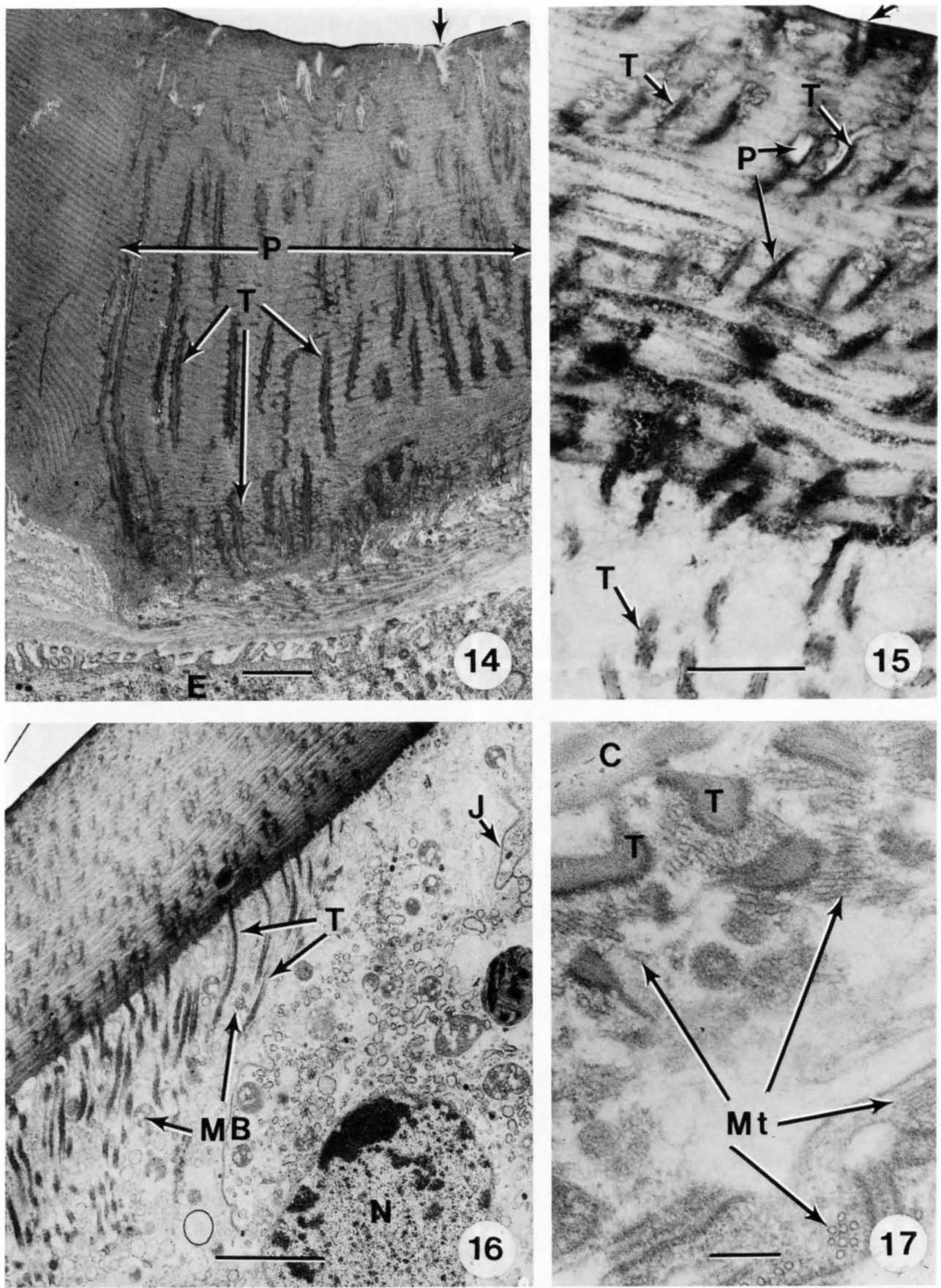

Fig. 14-17. (14) Cuticle near the edge of a plaque from female $T$. nigrovittatus. The cuticle of the plaque (P) is embedded with numerous tonofibrillae (T) structures which continue to the underlying epidermal cell (E). Some of the tonofibrillae run to the surface of the cuticle (short arrow), whereas the cuticle adjacent to the plaque lacks the tonofibrillae. Note the length of the tonofibrillae. Bar, $1.0 \mu \mathrm{m}$. (15) Higher magnification of cuticle (shown in Fig. 14) of a plaque showing tonofibrillae (T) passing through the lumen of a pore canal (P). Note each tonofibrilla consists of a thin continuous outer electron dense line and an inner, more homogenous rod. Bar, $1.0 \mu \mathrm{m}$. (16) Section through plaque showing that the long tonofibrillae $(T)$ are continuous with the specialized tendinous epidermal cell beneath the plaque. A nucleus (N), many multivesicular bodies (MB), and a cell junction (J) are present. Bar, $5 \mu \mathrm{m}$. (17) Higher magnification of a section at the base of cuticle (C) showing the organization of tonofibrillae (T) in a tendinous epidermal cell. Tonofibrillae consist of an outer electron dense line and the inner, more homogenous rod. Note that the numerous microtubules (MT) are closely related to the tonofibrillae. Bar, $2 \mu \mathrm{m}$. 
mvofibrils of the underlying muscles and the vertically oriented muscle attachment fibers of the overlying cuticle (i.e., the plaques of this study) (Lai-Fook 1967, Caveney 1969). As in other arthropods, the tonofibrillae (=microtubules of the tendinous epidermal cells and the muscle attachment fibers of the overlying cuticle) provide attachment sites for the underlying muscles (LaiFook 1967, Caveney 1969). Our TEM studies also confirmed (as has been found in other insects) that the muscle attachment fibers of the cuticle are narrower in cross section $(210 \AA)$ than in the microtubules $(230 \AA)$ of the tendinous epidermal cells, that the attachment fibers pass through the cuticle inside pore canals (Fig. 15), and that they terminate just below the cuticulin layer (Fig. 15).

The pore canals varied in size (700-1,400 $\AA$ ), and the diameter of the external pores or pitting of the plaques was about $950 \AA$. This measurement of the pores from our TEM studies (Fig. 15) correlates with our SEM studies (Fig. 5) - the size of the pores, using SEM, measured about the same as that obtained from our TEM measurements. Consequently, the pitting of the plaques, which can be seen only at high magnification using SEM, can now be explained based on other studies. Lai-Fook (1967) showed that these interruptions in the epicuticle (compare Fig. 5 and 15) are caused by the tonofibrillae. Other ultrastructural features are multivesicular bodies in the tendinous epidermal cells and numerous gap junctions attaching the tendinous epidermal cells to their neighbors (Fig. 16). According to Locke (1967), all epidermal cells contain multivesicular bodies and presumably are involved in storing and breaking down protein taken up from the hemolymph.

We have shown thus far that the pitting of the plaques is caused by the tonofibrillae, which pass from the epicuticle region through the cuticle and into the underlying epidermal cells. Here they take on a different structure. It appears that these tendinous epidermal cells are programmed to provide the insect with muscle attachment devices. Locke (1967) does not discuss this particular aspect of the functions of epidermal cells, but it would be most interesting to know what determines the fate of tendinous epidermal cells: Is it the contact with the muscle fiber?

What then was the function of the muscles attached to these plaques? Examination of adult $T$. nigrovittatus failed to show such muscles. Could muscles once attached subsequently have degenerated? By examining diverse groups of adult Diptera, we were able to formulate an hypothesis to account for the presence of these plaques, which occur only in the nematocerous and "orthorrhaphous" brachycerous flies. We propose that these plaques are regions of cuticle above tendinous epidermal cells that once possessed special muscle sets used by the pupa for abdominal movements and for eclosion of the pharate adult. Because the cuticle of the pharate adult is closely appressed to the pupal cuticle in these areas, bare, shiny plaques result in the fully hardened adult. Once the adult has emerged, the muscle sets degenerate.

The majority of nematocerous and brachycerous pupae is active throughout development and, in particular, all these pupae use abdominal movements to move from the location of their development (i.e., deep in soil, below the water surface, etc.) to the site of adult emergence. It is this group of Diptera to which abdominal plaques are restricted. We propose that the adult abdominal plaques are the sites of abdominal muscles that ensure this continuous pupal mobility. The Blephariceridae and Deuterophlebiidae may lack plaques because their pupae are firmly cemented to rocks in streams and rivers; thus these flies probably do not move their abdomens. The absence of plaques in the few other nematocerous groups in which we failed to find them is, however, inexplicable.

The major exception to pupal abdominal movement within the Diptera is in the Muscomorpha, including Aschiza. These flies have immobile pupae enclosed in a puparium formed from the last larval cuticle. We have not found abdominal plaques in any Muscomorpha, and we suggest that this reflects lack of pupal movement and consequent loss of attachment of abdominal muscles to the pupal cuticle in the pharate adult.

In a comparable case, the abdominal cuticle of pupal chironomids (Nematocera) exhibits bare cuticular areas that we believe are analogous with the plaques found in adults. They are arranged somewhat more evenly on the pupa (see Borkent 1984, Fig. 56E) than on adult tergites but otherwise resemble the plaques on slide-mounted adult Nematocera. Many chironomid larvae move their abdomens continuously (probably to ensure adequate respiration) and do so before, during, and after pupal emergence. Such movement is probably accomplished by pupal abdominal muscles anchored to the larval cuticle and is reflected by the presence of pupal plaque areas. Hinton (1958) discussed similar muscles in simuliids which are carried over from the larva to the pupal stage.

We propose that in addition to aiding in pupal locomotion, the muscles attached to the plaques in Nematocera and Brachycera "Orthorrhapha" assist the pharate adult in rupturing the pupal case (by increasing internal hemolymph pressure) and assist the pharate adult in inching its way out of the pupal case.

Several investigators have demonstrated in widely diverse insect groups that specific muscle sets are used to emerge from the cocoon or a cuticular structure encasing the new instar (Finlayson 1975). In addition, these same studies showed that, following emergence, these muscle sets undergo programmed cell death (Finlayson 1975).

As far as we are aware, no reports have been made concerning the mechanism(s) used by the more primitive dipterans to emerge from their $\mathrm{pu}-$ 
pal and puparial cuticles. However, flies in the Muscomorpha Schizophora use specialized muscles in the abdomen (Cottrell 1962) to increase hemolymph pressure in the head. This pressure extrudes the ptilinum (at the anterior region of the head) (Cottrell 1964), a structure that assists in breaking off the cap of the puparium. The Muscomorpha Aschiza have a puparium but lack a ptilinum. Presumably, increased hemolymph pressure in the head region is involved in adult eclosion, as the anterior end of the puparium is popped off. We suggest that in all Muscomorpha the plaques have been lost, because the pupae no longer move and the abdominal muscles are no longer attached to the pupal cuticle. The muscles apparently still function in adult eclosion by increasing hydrostatic pressure in the head region and degenerate shortly after adult emergence (Cottrell 1962).

Regardless of the function of the plaques, it seems quite clear that the universal loss of the plaques in Muscomorpha is a synapomorphy for the infraorder. It has recently been speculated that the Atelestus group of genera in the Empididae ("Atelestidae" of Chvála 1983), a putative sister group of the Muscomorpha, might pupate within a puparium in a fashion similar to that found in the Muscomorpha (Kovalev 1987). Because abdominal plaques occur in all three genera of the group (Atelestus Walker, Acarteroptera Collin, and Meghyperus Loew), we consider this quite unlikely. That the Atelestus group belongs within the Empidoidea rather than being a clade grouped with the Muscomorpha is further supported by the presence of only one spermatheca in females (at least in Atelestus Chandler 1981), a synapomorphy of the Empidoidea.

We hope that this study, in addition to disproving Bromley's contention that these cuticular plaques have a sensory function, will stimulate others to investigate the specific function of these muscle sets and their cuticular manifestations in nematocerous and orthorrhaphous brachycerous Diptera.

\section{Acknowledgment}

We thank J. Cumming for helpful discussions, especially concerning Empidoidea. This study was supported by Hatch Grant 571 to J.G.S. Paper No. 2825, Massachusetts Agricultural Experiment Station, University of Massachusetts, Amherst, and the Massachusetts Agricultural Experiment Station Electron Microscopy Lab.

\section{References Cited}

Borkent, A. 1984. The systematics and phylogeny of the Stenochironomus complex (Xestochironomus,
Harrisius, and Stenochironomus) (Diptera: Chironomidae). Memoirs of the Entomological Society of Canada 128.

Bromley, S. W. 1926. The external anatomy of the black horse-fly Tabanus atratus Fab. (Diptera: Tabanidae). Ann. Entomol. Soc. Am. 14: 440-460.

Caveney, S. 1969. Muscle attachment related to cuticle architecture in Apterygota. J. Cell Sci. 4: 541559 .

Chandler, P. 1981. Nemedina almirabilis sp. n., a new genus and species of Diptera Eremoneura, of uncertain affinities, from Hungary. Acta Zool. Acad. Sci. Hung. 27: 103-113.

Chvála, M. 1983. The Empidoidea (Diptera) of Fennoscandia and Denmark. II. General part. The families Hybotidae, Atelestidae and Microphoridae, vol. 12. In Fauna Entomologica Scandinavica. Scandinavian Science Press, Klampenborg, Denmark.

Cottrell, C. B. 1962. The imaginal ecdysis of blowflies. Observations on the hydrostatic mechanisms involved in digging and expansion. J. Exp. Biol. 39: 431-448.

1964. Insect ecdysis with particular emphasis on cuticular hardening and darkening. Adv. Insect Physiol. 2: $175-218$.

Dethier, V. G. 1957. The sensory physiology of bloodsucking arthropods. Exp. Parasitol. 6: 68-122.

Evans, W. G. \& J. E. Kuster. 1980. The infrared receptive fields of Melanophila acuminata (Coleoptera: Buprestidae). Can. Entomol. 112: 211-216.

Finlayson, L. H. 1975. Development and degeneration, pp. 75-149. In P. N. R. Usherwood [ed.], Insect muscle. Academic, New York.

Granger, C. A. 1970. Trap design and color as factors in trapping the salt marsh greenhead fly. J. Econ. Entomol. 63: 1670-1672.

Harris, R. A. 1979. A glossary of surface sculpturing. Laboratory Services, California Department of Food and Agriculture, Division of Plant Industry, Sacramento, Calif. Occasional Papers in Entomology 28.

Hinton, H. E. 1958. The pupa of the fly Simulium feeds and spins its own cocoon. Entomol. Mon. Mag. 94: 14-16.

Kovalev, V. G. 1987. [Book review]. M. Chvála. 1983. The Empidoidea (Diptera) of Fennoscandia and Denmark. II. General part. The families Hybotidae, Atelestidae and Microphoridae. In Fauna Entomological Scandinavica, Vol. 12. Scandinavian Science Press, Klampenborg, Denmark. Entomol. Obozr. 66: 215218 [in Russian].

Lai-Fook, J. 1967. The structure of developing muscle insertions in insects. J. Morphol. 123: 503-528.

Locke, M. 1967. What every epidermal cell knows, pp. 69-82. In J. W. L. Beament \& J. E. Treherne [eds.], Insects and physiology. Oliver \& Boyd, Edinburgh, Scotland.

McAlpine, J. F., B. V. Peterson, G. E. Shewell, H. J. Teskey, J. R. Vockeroth \& D. M. Wood [eds.]. 1981. Manual of Nearctic Diptera, vol. 1. Research Branch, Agriculture Canada, Monograph 27, Ottawa.

Received for publication 2 April 1987; accepted 28 December 1987. 